\author{
В.С. Лютенко, А.М. Яковенко
}

Полтавський національний технічний університет імені Юрія Кондратюка, Полтава

\title{
МАТЕМАТИЧНА МОДЕЛЬ ДЛЯ ДОСЛІДЖЕННЯ МЕХАНІЗМУ ПРИВОДА РОТОРА РОТОРНОГО ЕКСКАВАТОРА ЕР-315
}

Запропонована методика розрахунку динамічних навантажень у електромашинній та механічній системах привода ротора екскаватора. В методиці враховуються електромагнітні прочеси у двигуні, податливість пружних ланок, коливання мас, демпфування у пружних ланках. Наведені результати розрахунків перехідни прочесів у електромашинній та механічній системах.

Ключові слова: математична модель, екскаватор, привод ротора, механічна, електромашинна системи, динамічні навантаження, податливість, коливальні явища.

\section{Вступ}

У дорожньо-будівельному виробництві, аграрному комплексі та гірничо-видобувній промисловості важливе місце займає використання роторних екскаваторів. Раціональне їх використання дає можливість значно підвищити ефективність виконуваних робіт.

У металургії важливе місце займає виробництво вогнетривких виробів. Для їх виготовлення необхідна сировина яка також видобувається із використанням роторних екскаваторів.

Створення раціональних і оригінальних конструкцій роторних екскаваторів в значній мірі залежить від уміння зіставляти уже відомі варіанти i вводити нові, що відповідають високому рівню сучасної техніки.

Удосконалення привода ротора роторного екскаватора також нерозривно пов'язано із вивченням питань динаміки і міцності привідних систем.

Огляд останніх джерел досліджень і публікацій. Створення нових типів машин, а також удосконалення існуючих постійно вимагають уточнення методів їх розрахунку, що також пов'язано із необхідністю вивчення питань динаміки.

Вперше на динаміку процесу роторних екскаваторів звернув увагу L. Rasper [4], який відмітив коливання роторних стріл, визваних «резонуванням». Серйозні динамічні проблеми виникли на початку 1960-х років з початком будівництва і широкого використання роторних екскаваторів на відкритих гірничих роботах в СРСР для екскавації порід, кам'яного і бурого вугілля в районах Сибіру, Далекого сходу і Казахстану. Складні умови експлуатації і висока динамічність процесу приводили до вимушеного обмеження режиму роботи машини i, при цьому, до зниження продуктивності і економічним втратам [1, 2, 5].

Постала необхідність дослідження динаміки роторних екскаваторів і знаходження раціональних шляхів усунення коливань.
Великий вклад в вирішенні питань динаміки роторних екскаваторів вніс учений В.Ю. Чудновський [6 - 11]. Так в праці [6] ним розроблена схема робочих рухів і пружних коливань ротора у вибої та визначені під навантаженням додаткових шість віртуальних пружних переміщень.

У праці [7 - 9] приведені результати розроблення і впровадження ковшів ступінчастого різання місткістю $0,12 \mathrm{~m}^{3}$ з самозаточуючими зубами до роторних екскаваторів ЕР-315, ЕРП-315, які розроблені під його керівництвом. Нове ріжуче обладнання показало зниження сили різання, динамічності навантаження головних приводів і підвищення продуктивності машини.

Виділення невирішених раніше частин загальної проблеми. У даний час вивчення вимагає характер навантаження ротора екскаватора при перехідних процесах, особливо при пуску його привода.

При створенні адекватних фізичному процесу математичних моделей приводу ротора розглядаються відокремлено механічні і електромашинна системи, що не дає можливості реально оцінити електромеханічний об'єкт і спільно розглянути механічні і електромагнітні коливальні явища.

У свій час В.Ю. Чудновський $[10,11]$ дослідив динаміку головного привода ротора роторних екскаваторів 3 жорстко і пружно установленим редуктором.

Автором розроблена схема заміщення електромеханічної системи привода робочого органу (ротора) і складена система диференційних рівнянь руху мас цієї системи. Наряду з позитивним рішенням поставленої задачі необхідно відмітити, що використана автором залежність:

$$
\mathrm{M}_{\Pi}=\mathrm{M}_{\Pi}(\mathrm{t})+\mu_{\Pi} \phi_{2}=\mathrm{M}_{\kappa} \mathrm{i}_{\Pi} \eta_{\Pi}\left(1-\omega_{\mathrm{B}} / \omega_{0}\right)+\mu_{\Pi} \phi_{2},
$$

де $\mathrm{M}_{\kappa}, \omega_{0}$ - момент короткого замикання і частота обертання холостого ходу електродвигуна; $\omega_{\text {в }}$ номінальна частота обертання електродвигуна; $\mathrm{i}_{\text {п }}$, $\eta_{п}$ - передавальне число і ККД механізму привода; 
$\mu_{\Pi}-$ коефіцієнт дисипативних втрат приводу; $\phi_{2}-$ кутова швидкість приводу, не дає можливості ураховувати електромагнітні перехідні процеси в електроприводі (у привідному електродвигуні ротора) у тому числі - значення постійних і критичного моменту електродвигуна, а також - критичного ковзання ротора.

Дана робота і направлена на вирішення, з використанням застосунку MathCAD, питань динаміки привода ротора роторного екскаватора ЕP - 315 де 6 враховувались електромагнітні перехідні процеси в електроприводі (в привідному електродвигуні).

Постановка завдання Метою цієї роботи $є$ створення адекватної фізичному процесу моделі привода ротора роторного екскаватора, що являє собою електромеханічний об'єкт, на основі спільного розгляду механічних і електромагнітних коливальних явищ.

\section{Виклад основного матеріалу}

Роторні екскаватори являють собою складну механічну систему, яка дозволяє успішно виконувати землерийні роботи в карьєрах і при виконанні різноманітних робіт в будівництві, в тому числі - у аграрному секторі.

Як уже відзначалось, у екскаваторах використовуються приводи двох типів: електропривід, а також двигуни внутрішнього згорання.

В роторному екскаваторі, який ми розглядаємо, використовується електропривід.

Можно константувати, що під час роботи роторного екскаватора виконується різання грунтів (сировини) і переміщення їх в відвал, або транспортний засіб.

Нами розглядається динаміка процесу різання грунтів (сировини) ковшами ротора роторного екскаватора.

Оскільки роторний екскаватор являє собою пружну систему, яка складається 3 металевих конструкцій і приводів, навантажувальні фактори котрої змінюються в часі й за напрямком, то при різанні грунтів (сировини) неминучі коливання, у результаті чого в ланках виникають додаткові динамічні навантаження.

Для значного спрощення процесу досліджень нами використане математичне моделювання.

Існуючі роторні екскаватори являють собою пружну багатомасову систему з нескінченним числом ступенів вільності. Маси, що входять у систему, мають зосереджені й розподілені параметри.

Враховуючи особливості конструкції роторних екскаваторів, їх динаміку розглядаємо при деяких допущеннях.

1. При приведенні мас обертових елементів привода ротора екскаватора не беруться до уваги пружні властивості передач привода, оскільки їхні жорсткості в багато разів вищі за жорсткості конструкцій самого роторного екскаватора: враховується також відсутність проміжків у кінематичній схемі привода й синхронне переміщення мас, що приводяться.

2. У деяких випадках не враховується загасання коливань від зовнішнього та внутрішнього тертя у зв'язку з тим, що у початковому періоді при невеликих значеннях сили опору вони майже не впливають на коливальні процеси.

3. Припускаємо, що у процесі коливань існує лінійна залежність між зусиллями і деформаціями.

Перехідні процеси, що мають місце у роботі привідних механізмів роторів екскаваторів, значною мірою визначають динамічні навантаження в елементах розглянутих систем. На динаміку процесів пуску й зупинення механізму привода ротора екскаватора істотно впливають інерційні й жорсткісні параметри елементів системи. Пуск і зупинення приводу ротора виконується при завантажених ковшах.

При розгляді динамічних явищ, які виникають під час пуску привода екскаватора, за основний випадок умов навантаження приймемо поворот 3 завантаженими ковшами ротора при різанні грунтів. Розрахункова схема представлена на рис. 1 , де $\mathrm{J}_{\mathrm{pd}}-$ момент інерції ротора електродвигуна приведений до вісі обертання ротора екскаватора з урахуванням мас механізмів, що обертаються; $\mathrm{J}_{\mathrm{pe}}$ - сумарний момент інерції ротора 3 завантаженими ковшами відносно вісі обертання ротора екскаватоpa; $\mathrm{Y}_{\mathrm{pd}}, \mathrm{Y}_{\mathrm{pe}}$ - координати руху зосереджених мас (кути відліку); $\mathrm{C}_{\mathrm{n}}$ - приведена жорсткість привідної частини ротора екскаватора.

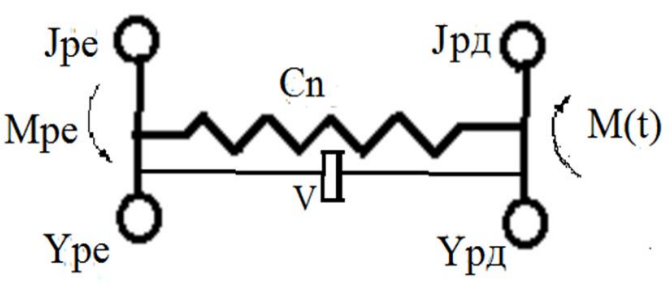

Рис. 1. Розрахункова схема навантаження механізму привода ротора екскаватора під час пуску привідного механізму

Приведення всіх мас системи, жорсткостей пружних ланок, а також сил робимо до вісі обертання ротора екскаватора.

Рівняння руху запишемо в такому вигляді:

$$
\begin{aligned}
& \mathrm{J}_{\mathrm{pd}} \cdot \mathrm{Y}_{\mathrm{pd}}^{\prime \prime}+\mathrm{C}_{\mathrm{n}}\left(\mathrm{Y}_{\mathrm{pd}}-\mathrm{Y}_{\mathrm{pe}}\right)+v\left(\mathrm{Y}_{\mathrm{pd}}^{\prime}-\mathrm{Y}_{\mathrm{pe}}^{\prime}\right)=\mathrm{M}(\mathrm{t}), \\
& \mathrm{J}_{\mathrm{pe}} \cdot \mathrm{Y}_{\mathrm{pe}}^{\prime \prime}-\mathrm{C}_{\mathrm{n}}\left(\mathrm{Y}_{\mathrm{pd}}-\mathrm{Y}_{\mathrm{pe}}\right)-v\left(\mathrm{Y}_{\mathrm{pd}}^{\prime}-\mathrm{Y}_{\mathrm{pe}}^{\prime}\right)=-\mathrm{M}_{\mathrm{pe}},
\end{aligned}
$$

Момент привідного електродвигуна виразимо диференціальною залежністю [3]: 


$$
M(t)=A_{0} u+A_{1} M^{\prime}(t)+A_{2} u^{2} Y_{p d}^{\prime}(t)
$$

де $\mathrm{Y}_{\mathrm{pd}}, \mathrm{Y}_{\mathrm{pe}}, \mathrm{Y}_{\mathrm{pd}}^{\prime}, \mathrm{Y}_{\mathrm{pe}}^{\prime}$ - кутове переміщення і кутова швидкість мас $J_{p d}$ i $J_{\text {pe }}$ у напрямку повороту ротора; v- коефіцієнт, що характеризує загасання; $\mathrm{M}_{\mathrm{pe}}$ - момент опору, який створюють сили різання $\mathrm{i}$ вага ротора 3 грунтом (сировиною). $\mathrm{M}_{\mathrm{pe}}=55,12$ кНм [11]; $\mathrm{C}_{\Pi}-$ приведена жорсткість механізму привода ротора екскаватора, $\mathrm{C}_{\Pi}=1,1 \cdot 10^{8} \mathrm{H} / \mathrm{m}$ [11]; u - передавальне число привода ротора, $\mathrm{u}=4,5 ; \mathrm{A}_{0}, \mathrm{~A}_{1}$, $\mathrm{A}_{2}$ - постійні електродвигуна. Значення постійних визначаються виразами:

$$
\mathrm{A}_{0}=\frac{2 \mathrm{M}_{\mathrm{k}}}{\mathrm{S}_{\mathrm{k}}} ; \quad \mathrm{A}_{1}=\frac{1}{\omega_{0} \mathrm{~S}_{\mathrm{k}}} ; \quad \mathrm{A}_{2}=\frac{2 \mathrm{M}_{\mathrm{k}}}{\omega_{0} \mathrm{~S}_{\mathrm{k}}},
$$

де $\mathrm{M}_{\mathrm{k}}$ - критичний момент електродвигуна; $\mathrm{S}_{\mathrm{k}}-$ критичне ковзання ротора електродвигуна; $\omega_{0}-$ синхронна кутова швидкість електродвигуна; $\mathrm{t}$ - час.

Межі використання рівняння (4) обмежуються значеннями моменту [3]

$$
-0,8 \mathrm{M}_{\mathrm{k}} \leq \mathrm{M} \leq 0,8 \mathrm{M}_{\mathrm{k}} .
$$

Початкові умови представимо у вигляді $(\mathrm{t}=0)$ $\mathrm{Y}_{\mathrm{pdo}}=0, \mathrm{Y}_{\text {peo }}=0, \mathrm{Y}_{\mathrm{pdo}}^{\prime}=0, \mathrm{Y}_{\mathrm{peo}}^{\prime}=0, \mathrm{M}_{0}=0$.

Для зручності рішення на ЕОМ системи рівнянь $з$ використанням застосунку MathCAD приводимо її до такого вигляду:

$$
\begin{aligned}
& J_{p d}(t) \cdot Y_{p d}^{\prime \prime}(t)+C_{n}\left[Y_{p d}(t)-Y_{p e}(t)\right]+ \\
& +v\left[Y_{p d}^{\prime}(t)-Y_{p e}^{\prime}(t)\right]=M(t) \text {; } \\
& J_{p e}(t) \cdot Y_{p e}^{\prime \prime}(t)-C_{n}\left[Y_{p d}(t)-Y_{p e}(t)\right]- \\
& -v\left[Y_{p d}^{\prime}(t)-Y_{p e}^{\prime}(t)\right]=-M_{p e} ; \\
& \mathrm{M}(\mathrm{t})=\mathrm{A}_{0} \mathrm{u}+\mathrm{A}_{1} \mathrm{M}^{\prime}(\mathrm{t})+\mathrm{A}_{2} \mathrm{u}^{2} \mathrm{Y}_{\mathrm{pd}}^{\prime}(\mathrm{t}) \text {. } \\
& \mathrm{z}^{\prime}(\mathrm{t})=\mathrm{d}(\mathrm{t}) ; \\
& d^{\prime}(t)=-\frac{C_{n}}{J_{p d}(t)} z(t)-\frac{v}{J p d(t)} d(t)+ \\
& +\frac{\mathrm{C}_{\mathrm{n}}}{\mathrm{J}_{\mathrm{pd}}(\mathrm{t})} \mathrm{q}(\mathrm{t})+\frac{\mathrm{v}}{\mathrm{J}_{\mathrm{pd}}(\mathrm{t})} \mathrm{n}(\mathrm{t})+\frac{\mathrm{u}}{\mathrm{Jpd}} \mathrm{M}(\mathrm{t}) \text {; } \\
& \mathrm{q}^{\prime}(\mathrm{t})=\mathrm{n}(\mathrm{t}) ; \\
& \mathrm{n}^{\prime}(\mathrm{t})=\frac{\mathrm{C}_{\mathrm{n}}}{\mathrm{J}_{\mathrm{pe}}(\mathrm{t})} \mathrm{z}(\mathrm{t})+\frac{\mathrm{v}}{\mathrm{J}_{\mathrm{pe}}(\mathrm{t})} \mathrm{d}(\mathrm{t})- \\
& -\frac{C_{n}}{J_{p e}(t)} q(t)-\frac{v}{J_{p e}(t)} n(t)-\frac{M_{p e}}{J_{p e}(t)} ; \\
& M^{\prime}(t)=-\frac{A_{2} u^{2}}{A_{1}} z(t)+\frac{1}{A_{1}} M(t)-\frac{A_{0} u}{A_{1}} ; \\
& \mathrm{k}(\mathrm{t})=\frac{\mathrm{uM}(\mathrm{t})}{\mathrm{J}_{\mathrm{pd}}(\mathrm{t})}-\frac{\mathrm{Y}_{\mathrm{pd}}(\mathrm{t}) \mathrm{C}_{\mathrm{n}}}{\mathrm{J}_{\mathrm{pd}}(\mathrm{t})}+\frac{\mathrm{Y}_{\mathrm{pe}}(\mathrm{t}) \mathrm{C}_{\mathrm{n}}}{\mathrm{J}_{\mathrm{pd}}(\mathrm{t})} \text {; }
\end{aligned}
$$


Побудований за виконаними розрахунками графік зміни моменту електродвигуна привода ротора у функції часу (рис. 3) показує, що розгін привода ротора триває близько 6 с від моменту його включення. Максимального значення момент досягає при $\mathrm{t}=1$ с від початку пуску.

Розв'язуючи, 3 використанням застосунку MathCAD, систему рівнянь (8) з добавленими рівняннями прискорень $\mathrm{K}(\mathrm{t})$ маси $\mathrm{Z}(\mathrm{t})=\mathrm{Y}_{\mathrm{pd}}(\mathrm{t})$ та $\mathrm{W}(\mathrm{t})$ маси $\mathrm{Q}(\mathrm{t})=\mathrm{Y}_{\mathrm{pe}}(\mathrm{t})$ нами отримано значення прискорень електродвигуна ротора екскаватора $\mathrm{K}(\mathrm{t})$ та самого ротора W(t) (рис. 2, а та 3, б).

Побудований за виконаними розрахунками графік зміни прискорень ротора екскаватора $\mathrm{W}(\mathrm{t})$ (рис. 2) показує, що прискорення має коливальний характер мас. Графіки (рис. 2) також показують, що після 6-7 с прискорення практично дорівнює нулю і рух набуває рівномірного характеру, як видно із графіка зміни моменту електродвигуна привода ротора $\mathrm{M}(\mathrm{t})$.

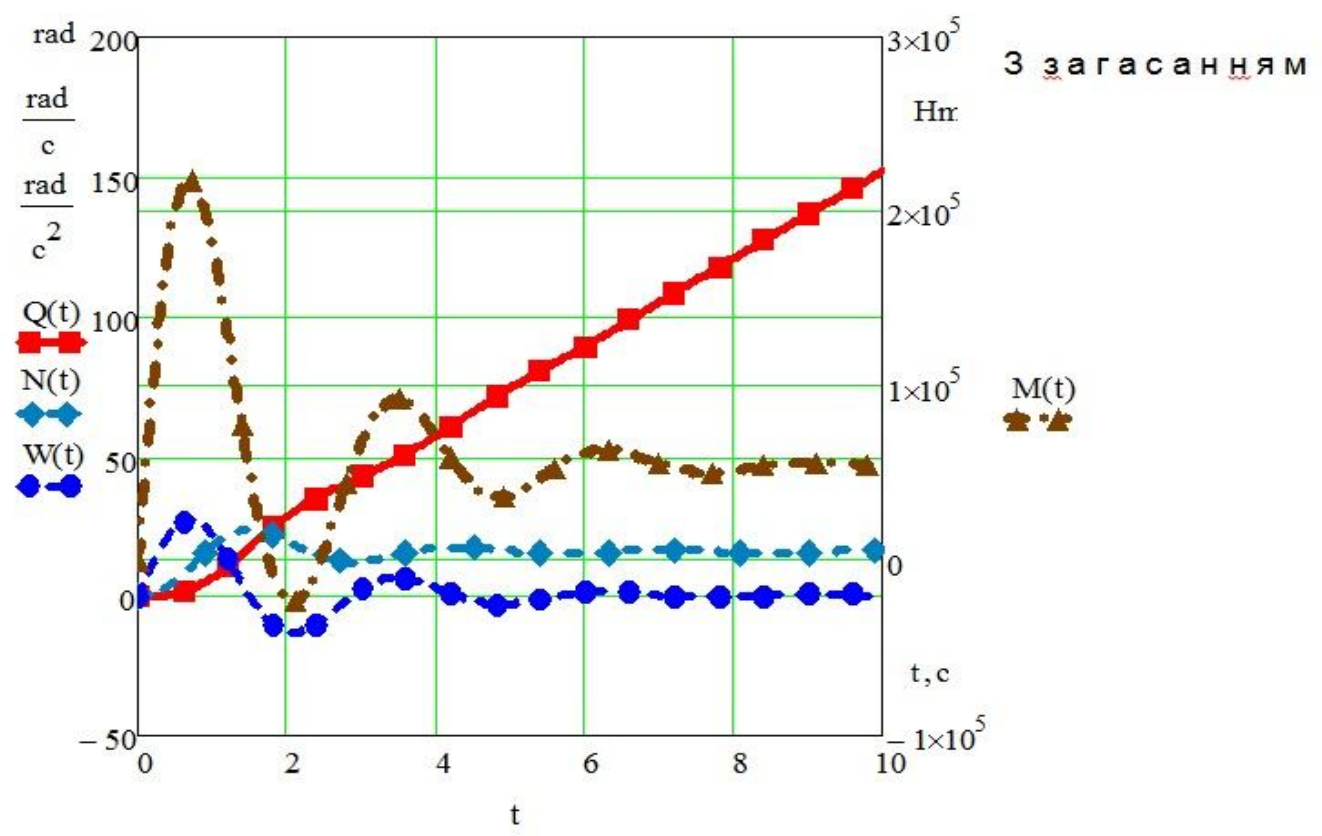

a

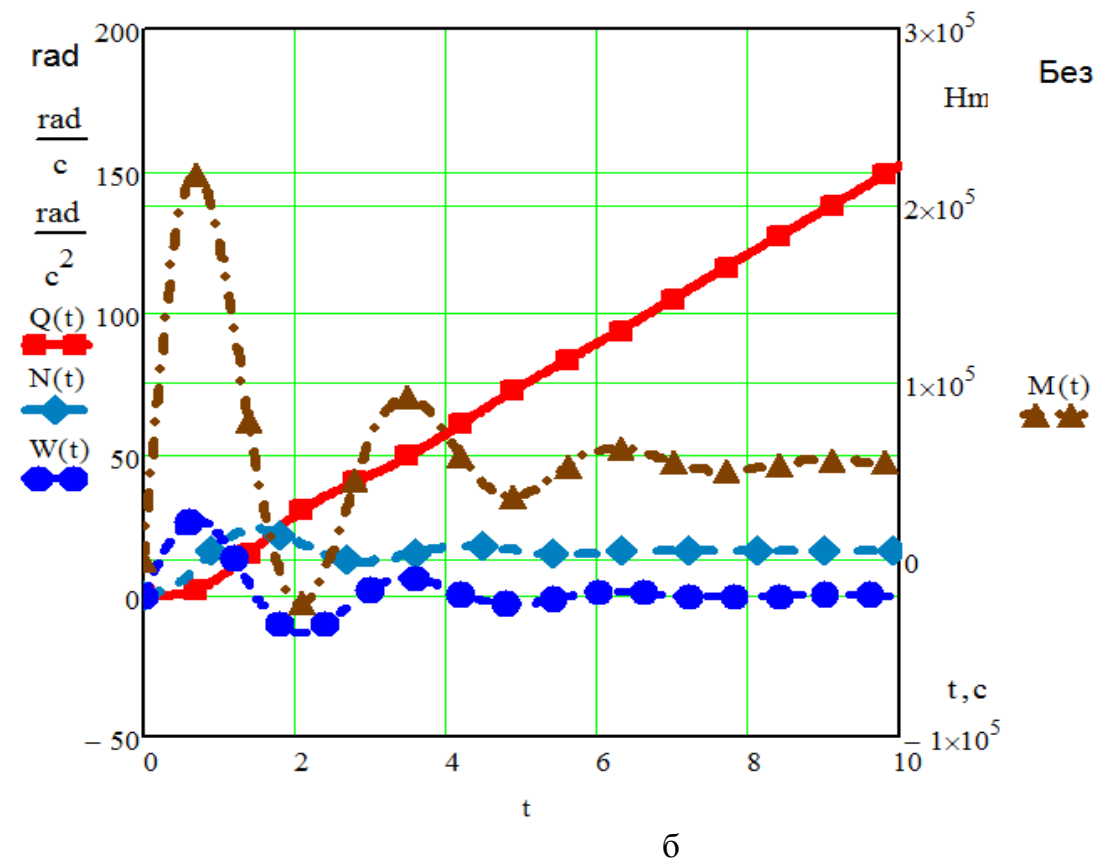

Рис. 2. Зміна кутового переміщення маси $\mathrm{Q}(\mathrm{t})=\mathrm{Y}_{\mathrm{pe}}$, кутової швидкості $\mathrm{N}(\mathrm{t})=\mathrm{Q}^{\prime}(\mathrm{t})=\mathrm{Y}_{\mathrm{pe}}^{\prime}$, кутового прискорення ротора екскаватора $\mathrm{W}(\mathrm{t})=\mathrm{Y}_{\mathrm{pe}}^{\prime \prime}(\mathrm{t})=\mathrm{N}^{\prime}(\mathrm{t})=\mathrm{Q}^{\prime \prime}(\mathrm{t})$ та моменту електродвигуна привода ротора $\mathrm{M}(\mathrm{t}): \mathrm{a}$ - iз загасанням; б - без загасання 

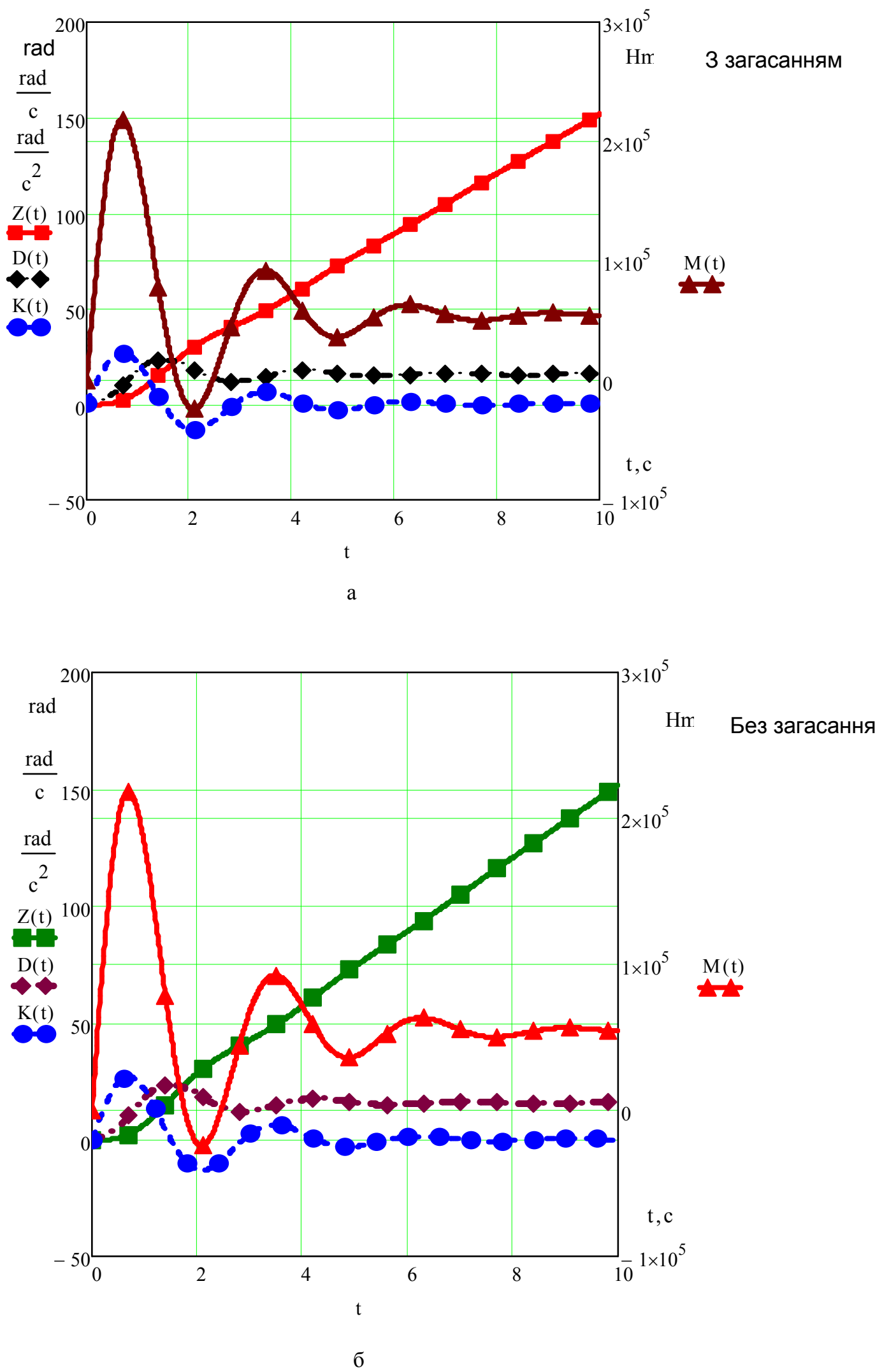

Рис. 3. Зміна кутового переміщення маси $Z(t)=Y_{p d}$, кутової швидкості $D(t)=Z^{\prime}(t)=Y_{p d}^{\prime}$, кутового прискорення ротора електродвигуна $\mathrm{K}(\mathrm{t})=\mathrm{Y}_{\mathrm{pd}}^{\prime \prime}(\mathrm{t})=\mathrm{D}^{\prime}(\mathrm{t})=\mathrm{Z}^{\prime \prime}(\mathrm{t})$ та моменту електродвигуна привода ротора $\mathrm{M}(\mathrm{t})$ : a - iз загасанням; б - без загасання 
Порівнюючи побудовані графіки, як з урахуванням загасання $v$ так і без нього, можна зробити висновок, що значення відрізняються несуттєво і визначені параметри мають більш точні значення при урахуванні загасання $v$.

Для перехідних процесів, показаних на рис. 2 та 3, характерне інтенсивне коливання електромагнітного моменту, кутової швидкості і прискорень електродвигуна, а також ротора екскаватора. Тому розрахунок робочих режимів роторних екскаваторів необхідно виконувати на основі рівнянь електромеханічного стану системи.

Використання числових методів інтегрування диференційних рівнянь руху i електромагнітного стану дозволяє використовувати запропоновану методику для розрахунку динамічних навантажень у електромашинній та механічній системах роторних екскаваторів.

\section{Висновки}

1. В роботі на основі аналізу тенденцій розвитку землерийних машин та існуючих технічних рішень роторних екскаваторів, а також з використанням математичного застосунку MathCAD досліджено механізм привода ротора роторного екскаватора $\mathrm{EP}-315$.

2. В роботі визначені сили різання, , а також теоретично досліджено, з використанням математичного програмного середовища MathCAD, динаміку механізму привода ротора роторного екскаватора.

3. Застосування числових методів інтегрування диференційних рівнянь руху i електромагнітного стану дозволяє використовувати запропоновану методику для розрахунку динамічних навантажень у електромашинній і механічній системах роторних екскаваторів.

4. Результати дослідження механізму привода ротора роторного екскаватора ЕР-315, з вико рис- танням математичного програмного середовища MathCAD, можуть бути використані при проектуванні, розрахунку та визначенні динамічних навантажень подібних землерийних машин.

\section{Список літератури}

1. Рабочие органы роторного экскаватора. Ю.И. Беляков, В.М. Владимиров. Москва «Машиностроение», 1967. $-372 \mathrm{c}$.

2. Совершенствование экскаваторных работ на карьерах. Ю.И. Беляков В.М.Владимиров. Москва «Недра», 1974.- $356 c$.

3. Ключев В.И. Ограничение динамических нагрузок электропривода / В.И. Ключев. - М.: Энергия, 1976. - 320 с.

4. Rasper L. Die Entwicklung der Schaufelradbagger in Deutschland// Braunkohle, 1955. Heft 19/20. St. 429- 441.

5. Владимиров В.М., Трофимов В.К. Повышение производительности карьерных многоковшовых экскаваторов. М.: Недра, 1980. -312 c.

6. Чудновский В.Ю. Динамические проблемы карьерных роторных экскаваторов и их решение // Горное оборудование и электромеханика. 2008. № 12. С. 33- 37.

7. Чудновский В.Ю. Механика роторных екскаваторов. Иерусалим: Изд-во МИКА К.А., 2002. - 329 с.

. Чудновский В.Ю. Основы рационального конструирования ковшей роторных экскаваторов // Горное оборудование и электромеханика. 2008. № 6. С. 2- 6.

9. Чудновский В.Ю. Приниипы конструирования самозатачивающегося режущегося инструмента роторных экскаваторов // Уголь. 2006. № 2. С. 16-20.

10. Чудновский В.Ю. Исследование динамики и устойчивости главного привода роторных экскаваторов с упругой подвеской редуктора//Горное оборудование и электромеханика. 2009. № 4. С. $46-49$.

11. Чудновский В.Ю. Динамика главного привода роторных экскаваторов с жостко установленным редуктором//Горное оборудование $u$ электромеханика. 2010. № 3. C. 44- 49.

Надійшла до редколегї 12.12.2017

Рецензент: д-р техн. наук, проф. Ю.Л. Винников, Полтавський національний технічний університет імені Юрія Кондратюка, Полтава.

\title{
МАТЕМАТИЧЕСКАЯ МОДЕЛЬ ДЛЯ ИССЛЕДОВАНИЯ МЕХАНИЗМА ПРИВОДА РОТОРА РОТОРНОГО ЭКСКАВАТОРА ЭР-315
}

\author{
В.Е. Лютенко, А.М. Яковенко
}

Предложена методика расчета динамических нагрузок в электромашинной и механической системах привода ротора экскаватора. В методике учитываются электромагнитные процессы в двигателе, податливость упругих звеньев, колебания масс, демпфирование в упругих связях. Приведены результаты расчетов переходных процессов в электромашинной и механической системах.

Ключевые слова: математическая модель, экскаватор, привод ротора, механическая, электромашинная системы, динамические нагрузки, податливость, колебательные явления.

\section{A MATHEMATIKAL MODEL FOR INVESTIGATING THE MECHANISM OF DRIVING F ROTARY EXCAVATOR ER-315}

V.Ye. Liutenko, A.M. Yakovenko

The proposed method for calculating dynamic loads in electric and mechanical sistems is a technique for calculating dynamic loas in eltctric and mechanical drives of an excavatjr rotor. The technique takes into account the electromagnetic processes in the engine, the elasticity of the elastic parts, the damping in the masses, and damping in the elastic links. Tht results of calculations of transients in electric and mechanical systems are presented.

Keywords: Mathmodel, excavator,transmission of rotary table, mechanical, systems of electrical machine, dynamical strain, pliability, vibration phenomena. 